\title{
Polycondensation of pyrrole and benzaldehyde catalyzed by Maghnite-H+
}

\author{
A. Belmokhtar ${ }^{1}$, N. Sahli ${ }^{1}$, A. Yahiaoui ${ }^{*} 1,2$, M. Belbachir ${ }^{1}$ \\ ${ }^{1}$ Laboratoire de Chimie des Polymères, Faculté des sciences, Université d'Oran, BP 1524 El-Menouer 31000 Oran, \\ Algérie \\ ${ }^{2}$ Centre Universitaire Mustapha Stambouli, Institut des Sciences et de Technologie, BP 763 Mascara 29000, Algérie
}

Received 5 April 2007; accepted in revised form 27 May 2007

\begin{abstract}
Rapid synthesis of poly[(pyrrole-2,5-diyl)-co-(benzylidene)] was achieved under microwave irradiation via the condensation of pyrrole and benzaldehyde in 1,2-dichloroethane using acid exchanged montmorillonite clay called Maghnite- $\mathrm{H}^{+}\left(\mathrm{Mag}-\mathrm{H}^{+}\right)$as an efficient catalyst. The effect of the amount of catalyst and of time on the polymerization yield and on the viscosity of the polymers was studied. Compared with conventional static interfacial polymerization, the microwaveradiation polymerization reaction proceeded rapidly and was completed within $35 \mathrm{~s}$. The conjugated polymer was characterized by means of ${ }^{1} \mathrm{H}-\mathrm{NMR}, \mathrm{X}$-ray diffraction, FT-IR spectroscopy and AFM. The X-ray data showed the presence of a backbone form of the [(pyrrole-2,5-diyl)-co-(benzylidene)] formed.
\end{abstract}

Keywords: polymer synthesis, molecular engineering, poly[(pyrrole-2,5-diyl)-co-(benzylidene)], Maghnite-H $H^{+}$, conjugated polymer, pyrrole

\section{Introduction}

Among conducting electroactive polymers, polypyrrole and its derivatives have received a great deal of attention due to its high electrical conductivity, good environmental stability, relative ease of synthesis and good redox reversibility. These properties are favourable to its applications in the areas of secondary batteries, electrocatalysis, electrochromic display devices, light-emitting devices, chemical sensors and biosensors [1-5]. However, polypyrrole and other conducting electroactive polymers are limited in practical use due to their very fragile structure and insolubility, which give rise to processing difficulties $[6,7]$. Several approaches have been taken to improve processability of conducting polymers [8-11]. One effective method is to introduce insulating polymeric matrices into them due to the excellent

"Corresponding author, e-mail: yahmeddz@yahoo.fr

(C) BME-PT and GTE processability of classical insulating polymers [12-18]. This can be achieved by blending, composite formation or copolymerization. Copolymerization could be a desirable way because the chemical linkage between the insulating matrix and the conjugated polymer can improve the chemical stability of the polymer $[17,18]$. The resulting copolymers with new functional groups showed different properties from polypyrrole homopolymer, which probably widen the application of conducting polymer.

Several kinds of copolymers containing pyrrole and other insulating units, such as styrene, tetrahydrofuran, methyl methacrylate, $\varepsilon$-caprolactone, acryloyl chloride, etc., have been prepared and studied [18-23]. All results showed the success in improving the mechanical and physical properties of polypyrrole. However, these synthetic methods contained many steps and strict condition, leading 


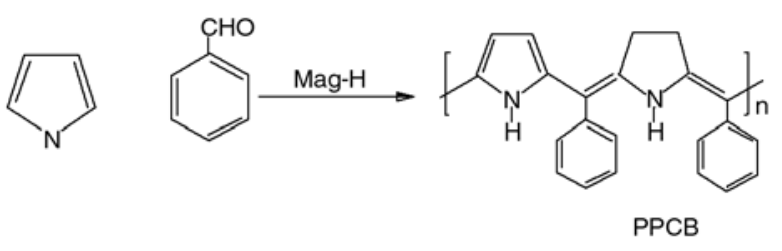

Figure 1. The synthetic route of poly[(pyrrole-2,5-diyl)co-(benzylidene)] (PPCB) by Mag- $\mathrm{H}^{+}$catalyst

to limited application of these copolymers. A simple and alternative way is direct electrochemical copolymerization of monomers present in the mixture in proper solution [24-26].

Recently, an Algerian proton exchanged montmorillonite clay called Maghnite- $\mathrm{H}^{+}\left(\mathrm{Mag}-\mathrm{H}^{+}\right)$, a new non toxic cationic initiator, was used as a catalyst for cationic polymerization of a number of vinylic and heterocyclic monomers [27-30].

In the present work, we present a new approach to design poly[(pyrrole-2,5-diyl)-co-(benzylidene)] (PPCB) in one shot, namely by the condensation of pyrrole and benzaldehyde catalyzed by $\mathrm{Mag}-\mathrm{H}^{+}$ (Figure 1). In contrast to most of the other conductive polymers, PPCB is a soluble polymer in common organic solvents. The catalyst can be easily separated from the polymer product and regenerated by heating at a temperature above $0^{\circ} \mathrm{C}$ [15].

The effects of different synthesis parameters, such as the amount of $\mathrm{Mag}-\mathrm{H}^{+}$, monomer, pyrrole, and benzaldehyde are discussed.

\section{Experimental}

\subsection{Materials}

Pyrrole was purchased from Aldrich Chemical Co. and distilled under reduced pressure. Dichloromethane and benzaldehyde were used as received. AFM imaging was performed on Hitachi 530 microscope (Digital Instruments) using a $10 \mu \mathrm{m} \times$ $10 \mu \mathrm{m}$ piezoelectric scanner. Images were collected using tapping mode AFM (TM-AFM) because it is particularly well adapted to soft samples due to a nearly complete reduction of lateral forces. Silicon tips with a spring constant of $42 \mathrm{~N} \cdot \mathrm{m}^{-1}$ and a resonance frequency of approximately $320 \mathrm{kHz}$ were used in tapping mode. To minimize the forces of interaction between the tip and samples, the ratio of the set point amplitude and the tip free amplitude was maintained at 0.9 ('light tapping'). The preparation technique was made by a drop deposition; a
$5 \mu \mathrm{l}$ sample was pipetted directly onto the mica surface.

The molecular structure of the polymer was characterized by FT-IR spectroscopy (Perkin-Elmer System). As a source of microwave irradiation, we used a Galanz domestic microwave oven $(2450 \mathrm{MHz}, 800 \mathrm{~W})$ device. UV spectra were obtained by an OPTIZEN 2120 UV-Vis spectrometer using the dichloromethane solution of polymers with a concentration of $0,00125 \mathrm{mg} / \mathrm{ml} .{ }^{1} \mathrm{H}$-nuclear magnetic resonance (NMR) measurements were carried out on a $300 \mathrm{MHz}$ Bruker NMR Spectrometer equipped with a probe $\mathrm{BB} 05 \mathrm{~mm}$, in $\mathrm{CDCl}_{3}$. Tetramethylsilane (TMS) was used as the internal standard in these cases.

$\mathrm{X}$-ray diffraction (XRD) patterns for Mag-H and poly[(pyrrole-2,5-diyl)-co-(benzylidene)] were obtained on a Philips analytical X-ray diffractometer $(\mathrm{Cu}$ anode, $35 \mathrm{kV}, 20 \mathrm{~mA})$.

\subsection{Polymer preparation}

In a $50 \mathrm{ml}$ beaker, pyrrole $(8 \mathrm{mmol})$ and benzaldehyde $(8 \mathrm{mmol})$ were dissolved in $10 \mathrm{ml}$ of $1,2-$ dichloroethane and a chosen amount of Maghnite- $\mathrm{H}^{+}$was added. The weight ratio (Maghnite- $\mathrm{H}^{+} / \mathrm{Py}$; BA) was kept constant (at the desired value) in all flask. The mixture was placed in a microwave oven to be irradiated at full power for less than one minute. At the end of the reaction, the resulting mixture was filtered to remove the clay and then slowly added to methanol with stirring and then the polymer was dried under vacuum at room temperature for $24 \mathrm{~h}$.

\section{Results and discussion}

Most of the PPCB were found to be soluble in organic solvents such as tetrahydrofuran (THF), $\mathrm{CH}_{2} \mathrm{Cl}_{2}$, N,N-dimethylformamide (DMF), and sulfolane. Although polymers have highly conjugated chains due to the high degree of dehydrogenation, they were very soluble in organic solvents such as THF, giving grey solutions of high concentrations. The very good solubility of polymers in spite of their high degree of $\pi$-conjugation is due largely to the bulky side groups $(\phi)$ at the methane carbon $=\mathrm{C}$ (申) link and also to the low molecular weight to some extent.

The UV-Vis absorption was recorded with an OPTIZEN 2120 spectrometer. Figure 2 shows the 

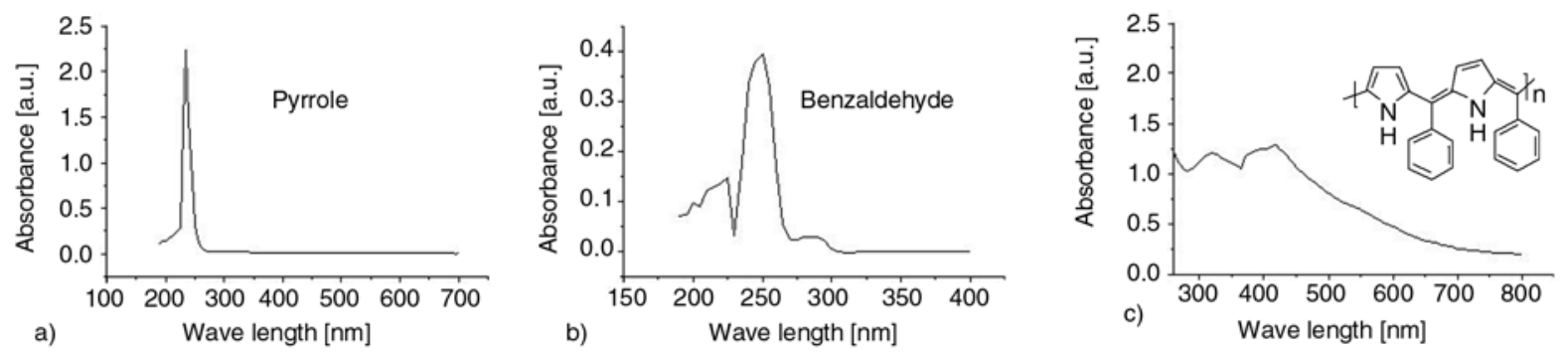

Figure 2. UV-Vis spectrum of PPCB (in $\mathrm{CH}_{2} \mathrm{Cl}_{2}$ )

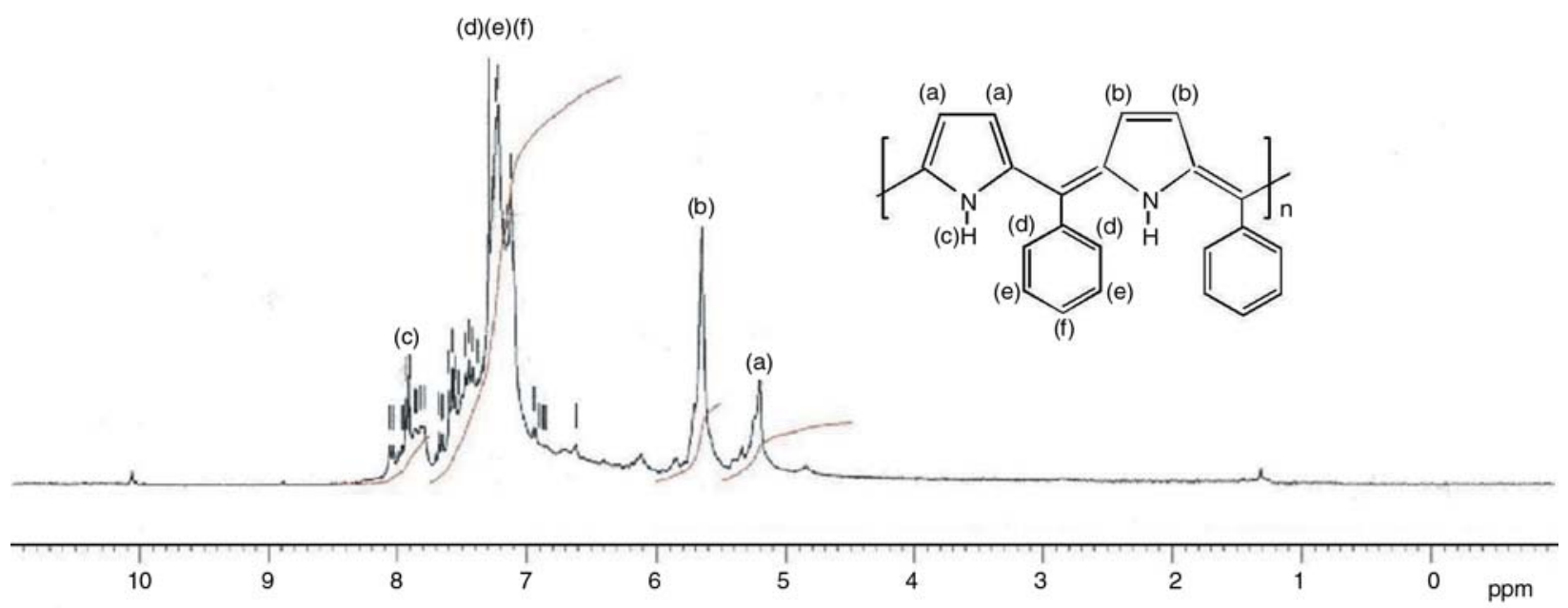

Figure 3. ${ }^{1} \mathrm{H}-\mathrm{NMR}$ spectrum $(300 \mathrm{MHz})$ of $\mathrm{PPCB}$ in $\mathrm{CDCl}_{3}$

optical absorption spectra of polymers PPCB in $\mathrm{CH}_{2} \mathrm{Cl}_{2}$ solution. The colours of the polymer solution were brown or almost black. The absorption spectra in Figure 2 shows the band in the range of (280-350) nm assigned to the $\pi-\pi^{*}$ transition of the aromatic heterocycles since it corresponds to the same band as its precursor, and the band in the range of (370-450) nm is assigned to the $\pi-\pi^{*}$ transition.

In ${ }^{1} \mathrm{H}-\mathrm{NMR}$ spectrum (Figure 3 ), the characteristic methine hydrogen resonance at about 4,47 ppm for precursors completely disappeared, but a new proton resonance of 7,2-7,8 ppm was observed, indicating the formation of the quinoid rings in the polymer backbone. The polymers so obtained are readily soluble in common organic solvents, such as chloroform, dichloromethane, THF.

Figure 4 presents the FTIR spectrum of PPCB, shows the appearance of a strong absorption at $1693 \mathrm{~cm}^{-1}$ which is attributed to the stretching vibration of conjugated $\mathrm{C}=\mathrm{C}$ and the stretching vibration of aromatic in phenylene. A distinct peak near $798 \mathrm{~cm}^{-1}$ is due the out of plane vibration $\mathrm{C}_{\beta}-\mathrm{H}$ characteristic of the $\alpha$-linkage in pyrrole

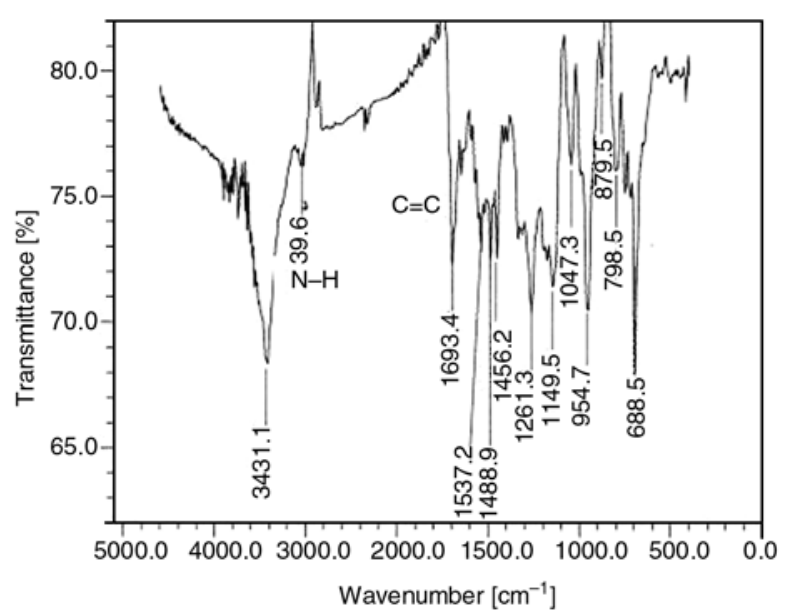

Figure 4. FT-IR spectrum of PPCB

rings. The peak at $3431 \mathrm{~cm}^{-1}$ is due the vibration of $\mathrm{N}-\mathrm{H}$ in pyrrole.

The FT-IR spectrum of PPCB is the same as that of poly[pyrrole-2,5-diyl(p-dimethyl amino benzylidene)] synthesized by classical polymerization described in the literature [31], in which the vibration of the phenylene conjugated $\mathrm{C}=\mathrm{C}$ and $\mathrm{C}_{\beta}-\mathrm{H}$ of the $\alpha$-linkage in pyrrole rings appeared at $1632 \mathrm{~cm}^{-1}$ and $780 \mathrm{~cm}^{-1}$ respectively. 


\subsection{X-ray diffraction analysis}

Intensity versus $2 \theta$ scans of Maghnite (before; Figure 5 and after polymerization; Figure 6) and PPCB (Figure 7) respectively indicate the presence of a backbone form of the polymer which generates sharp peaks at a high angle range $\sim 12^{\circ}-30^{\circ}$ (Figure 7). The X-ray peaks of the fresh and the recovered Maghnite- $\mathrm{H}^{+}$did not change. This implies that the original structure was well preserved after polymerization and no delamination of the clay was observed (Figure 6).

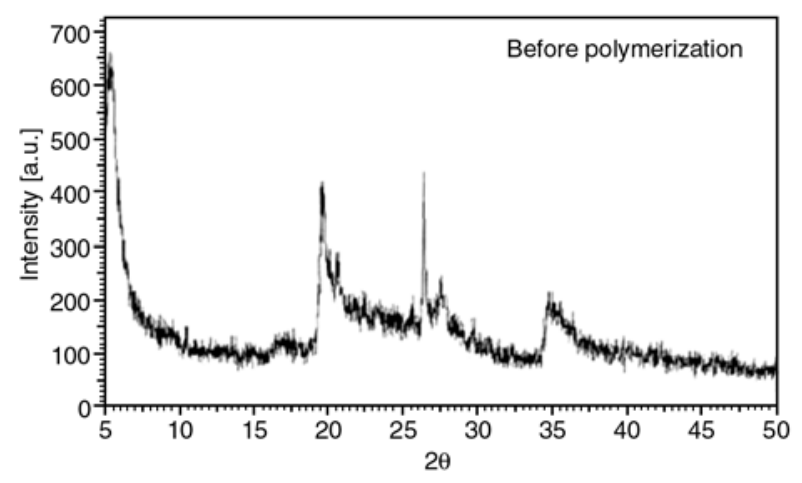

Figure 5. XRD scans: Maghnite before polymerization

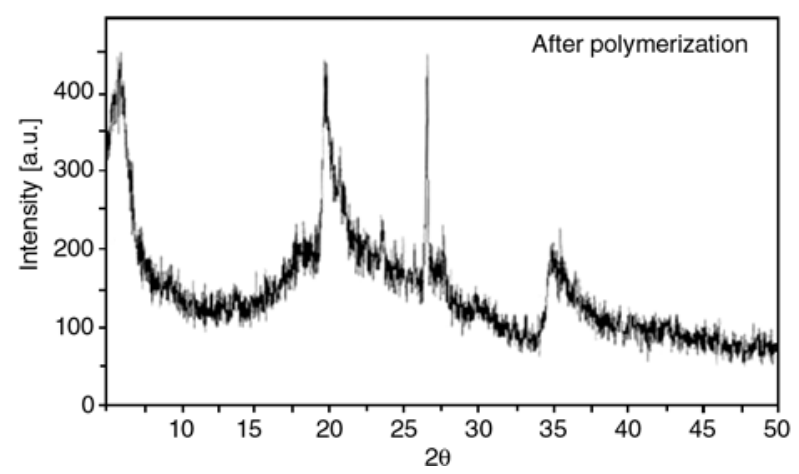

Figure 6. XRD scans: Maghnite after polymerization

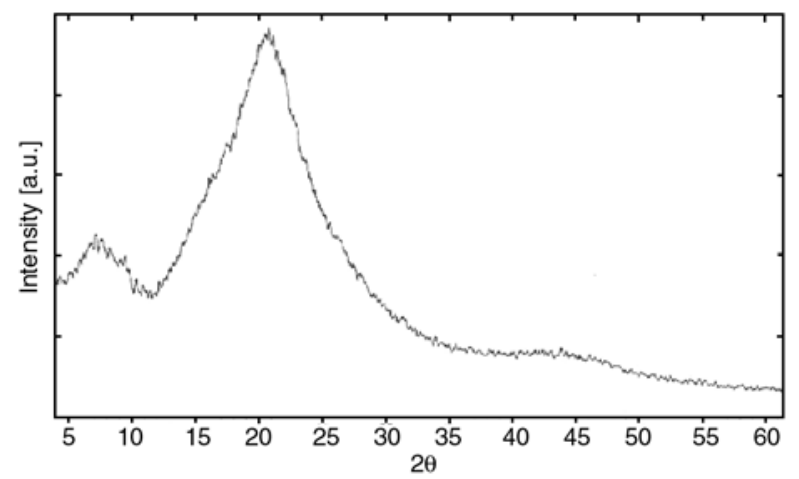

Figure 7. XRD scans of PPCB

\subsection{Effect of the amount of Mag- $\mathrm{H}^{+}$}

Figure 8 shows the effect of the amount of Mag $-\mathrm{H}^{+}$, expressed by using various weight ratios $\mathrm{Mag}-\mathrm{H}^{+} /$monomer, on the polymerization rate. The polymerization was carried out in bulk. As shown in Figure 8, a yield of $66 \mathrm{wt} \%$ was reached for $5 \mathrm{wt} \%$ of $\mathrm{Mag}-\mathrm{H}^{+}$, and the use of a lower or higher amount of clay caused a decrease of the yield of the reaction. Similar results are obtained by Yahiaoui et al. [32-35] in the polymerization of epichlorhydrin, propylene oxide and cyclohexene oxide by Mag $-\mathrm{H}^{+}$and the polymerization of styrene by montmorillonite, respectively. This phenomenon is probably the result of the number of 'initiating active sites' responsible of inducing polymerization, this number is prorating to the catalyst amount used in reaction.

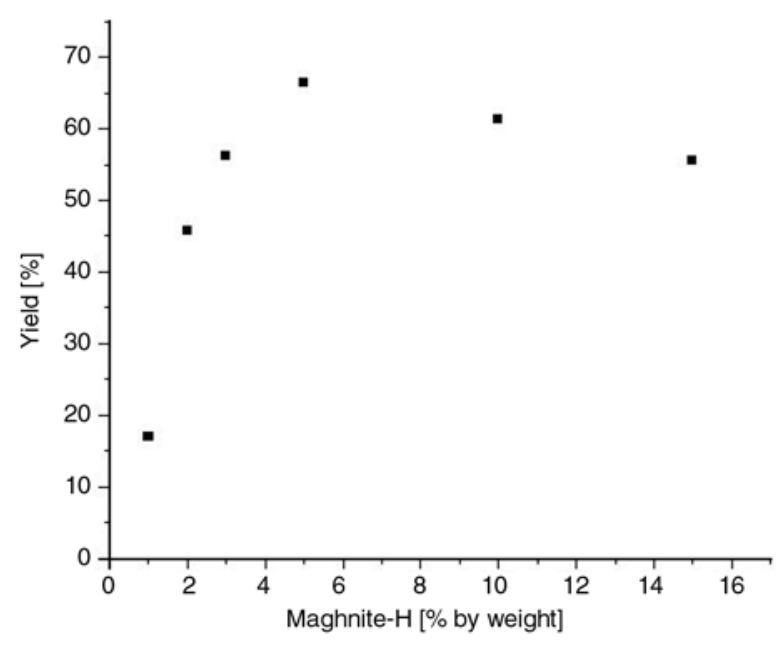

Figure 8. Effect of the amount of $\mathrm{Mag}-\mathrm{H}^{+}$on the yield of PPCB by microwave irradiation

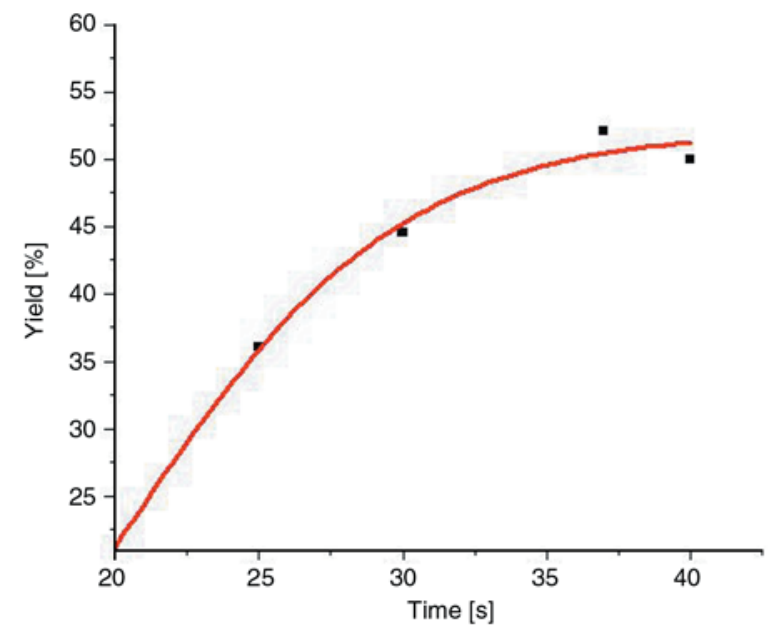

Figure 9. Yield of PPCB at Maghnite- $\mathrm{H}^{+}=5 \%$, $[$ benzaldehyde $]=[$ pyrrole $]=8 \cdot 10^{-3} \mathrm{~mol} / \mathrm{l}$, by microwave irradiation 


\subsection{Effect of time on condensation}

Figure 9 shows the yield of polymer versus time for polymerization of pyrrole using $\mathrm{Mag}-\mathrm{H}^{+}$as catalyst. As the figure shows, polymerization takes place rapidly and smoothly, reaching a conversion of $52 \%$ after $32 \mathrm{~s}$. The polymerization yield became constant at that time; this is probably the result of an increase in the medium viscosity.

\subsection{Effect of the [benzaldehyde]/pyrrole molar ratio on condensation of benzaldehyde and pyrrole}

In the presence of Maghnite- $\mathrm{H}^{+}$and using different [benzaldehyde]/[pyrrole] molar ratios, the condensation was carried out for $35 \mathrm{~s}$ with microwave irradiation. Figure 10 shows the effect of [benzaldehyde]/[pyrrole] molar ratio on the intrinsic viscosity.

It is well known that benzaldehyde on its own does not undergo polymerization under such polymer-

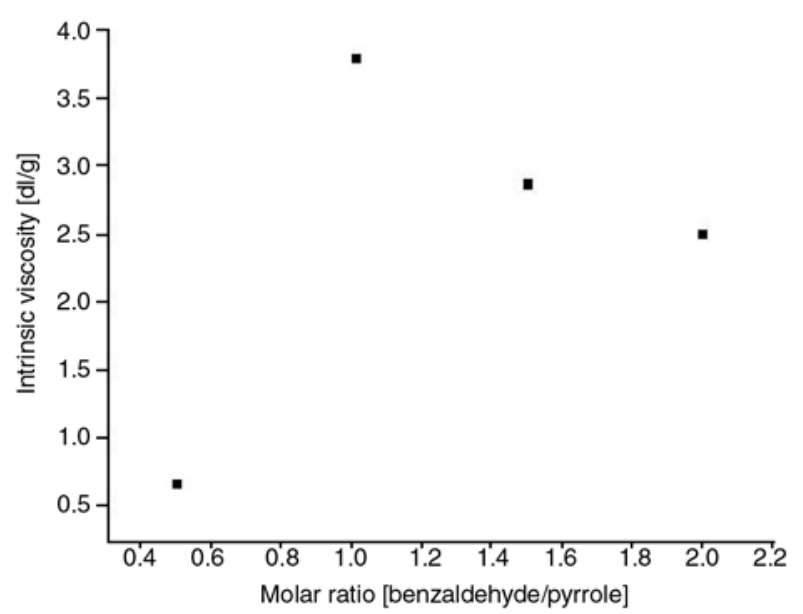

Figure 10. Intrinsic viscosities of PPCBs
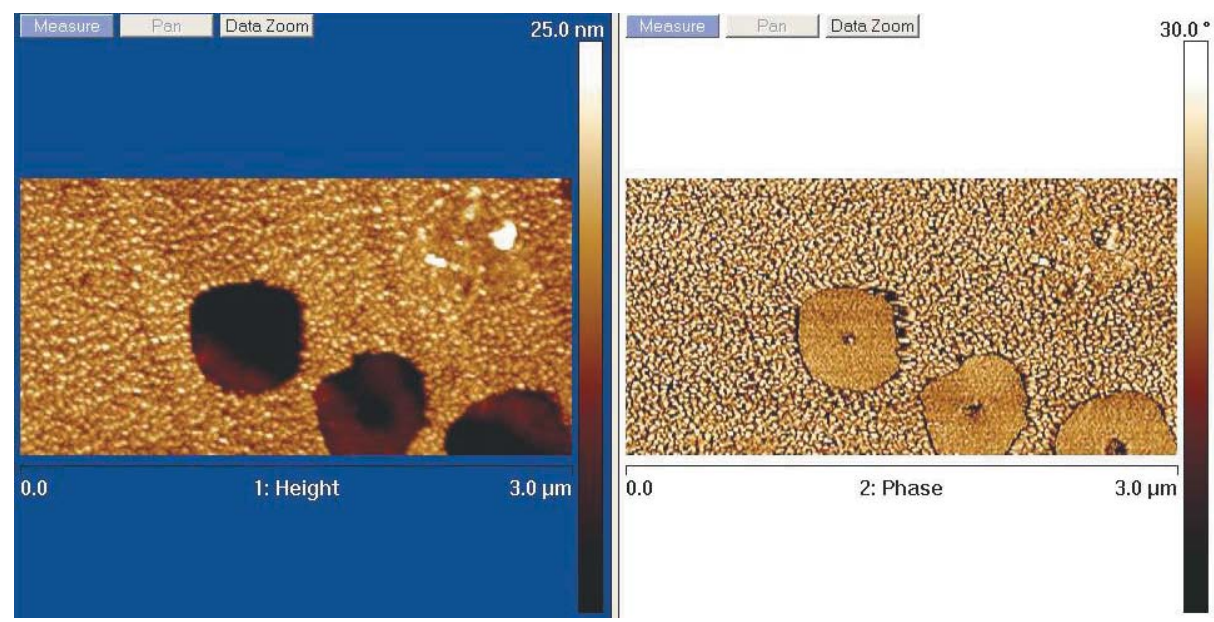

Figure 11. AFM image of PPCBs synthesized by the microwave irradiation polymerization in the presence of $\mathrm{Mag}-\mathrm{H}^{+}$as catalyst ization conditions. In fact, when the polymerization of benzaldehyde was performed in the presence of Mag $-\mathrm{H}^{+}$. The yields and $[\eta]$ values decrease with increasing the benzaldehyde ratios in the monomer feeds (Figure 10).

Compared with conventional methods such as interfacial polymerization [36], microwave-assisted copolymerization was more effective for the preparation of a higher yield, in shorter time (63\% in $35 \mathrm{~s})$. The higher yield under microwave irradiation suggested that microwave energy provides a more efficient synthetic route as a consequence of the direct interaction between microwaves and the molecular dipole moments of the reactants.

The intrinsic viscosities of the soluble PPCBs shown in Figure 10, give an indication of the molecular weight. The intrinsic viscosity values, which are in the range $0.9-0.38 \mathrm{dl} / \mathrm{g}$, indicate that the polymers have mostly low molecular weights. The low molecular weights obtained here are comparable to literature reports [37] for the polymers.

Typical AFM images of polymers microspheres are shown in Figure 11. The spheres diameters are in the range of $5 \mu \mathrm{m}$. It can be seen that some spheres connect with each other to form dumbbell or calabash structure, as pointed by arrows. We think this phenomen means these spheres' walls are made up of reactive polymers; they can continue to react with each other to form bigger spheres. The mechanism of the formation of PPCBs is under studying.

\section{Conclusions}

Maghnite- $\mathrm{H}^{+}$, proton exchanged montmorillonite clay is an effective initiator for the copolymeriza- 
tion of benzaldehyde with pyrrole by microwave irradiation.

A novel polymer, poly[(pyrrole-2,5-diyl)-co-(benzylidene)], which has a $\pi$-conjugated chain was synthesized by a microwave irradiation catalysed by Maghnite- $\mathrm{H}^{+}$. The resultant polymer showed good solubility in common organic solvents and good film formability. Such results may serve primarily to illustrate a new strategy to increase the solubility of low band gap polymers through the arrangement of different aromatic heterocycles in conjugated polymer backbones.

Compared with conventional static interfacial polymerization, the microwave-radiation polymerization reaction proceeded rapidly and was completed within $35 \mathrm{~s}$ giving a series of $0.5 \sim 5 \mu \mathrm{m}$ in diameter polymer microspheres.

\section{References}

[1] Mermilliod N., Tanguy J., Petiot F.: A study of chemically synthesized polypyrrole as electrode material for battery applications. Journal of the Electrochemical Society, 133, 1073-1079 (1986).

[2] MacDiarmid A. G., Epstein A. J.: Application of thin films of polyaniline and polypyrrole in novel lightemitting devices and liquid-crystal devices. Photonic and Optoelectronic Polymers, 672, 395-407 (1997).

[3] Mao H. Y., Pickup P. G.: Electronically conductive anion-exchange polymers based on polypyrrolepreparation, characterization, electrostatic binding of ferrocyanide and electrocatalysis of ascorbic-acid oxidation. Journal of Electroanalytical Chemistry and Interfacial Electrochemistry, 265, 127-142 (1989).

[4] Ramanavicius A., Ramanaviciene A., Malinauskas A.: Electrochemical sensors based on conducting polymer-polypyrrole. Electrochimica Acta, 51, 6025-6037 (2006).

[5] Xue H. G., Mu S. L.: Bioelectrochemical response of the polypyrrole xanthine-oxidase electrode. Journal of Electroanalytical Chemistry, 397, 241-247 (1995).

[6] Lindenberger H., Schafer-Siebert D., Roth S., Hanack M.: Synthesis and properties of polypyrrole prepared by electrochemical polymerization of alpha-bipyrrole. Synthetic Metals, 18, 37-41 (1987).

[7] Qian R. Y., Qiu J. J., Shen D. Y.: Conducting polypyrrole electrochemically prepared from aqueous-solutions. Synthetic Metals, 18, 13-18 (1987).

[8] De Paoli M. A., Gazotti W. A.: Conductive polymer blends: Preparation, properties and applications. Macromolecular Symposia, 189, 83-103 (2002).

[9] Li Y. F., Ouyang J. Y.: Effect of nonionic surfactant additives on the electropolymerization of pyrrole in aqueous solutions. Synthetic Metals, 113, 23-28 (2000).
[10] Corres M. A., Mulgica A., Carrasco P. M., Cortazar M. M.: Effect of crystallization on morphology-conductivity relationship in polypyrrole/poly(epsiloncaprolactone) blends. Polymer, 47, 6759-6764 (2006).

[11] Balci N., Toppare L., Akbulut U., Stanke D., Hallensleben M. L.: Polypyrrole grafts synthesized via electrochemical polymerization. Journal of Macromolecular Science: Pure and Applied Chemistry, 35, 1727-1739 (1998).

[12] Lee Y., Shin D., Cho J., Park Y. H., Son Y., Baik D. H.: Ionic interactions in polyacrylonitrile/polypyrrole conducting polymer composite. Journal of Applied Polymer Science, 69, 2641-2648 (1998).

[13] Levine K. L., Iroh J. O.: Resistance of the polypyrrole/polyimide composite by electrochemical impedance spectroscopy. Journal of Porous Materials, 11, 87-95 (2004).

[14] Yin W. S., Yan T. J., Gan L. M., Chew C. H., Liu H. W., Gan L. H.: Conductive composite films based on polypyrrole and crosslinked poly(styrene butyl acrylate acrylic acid). European Polymer Journal, 34, 1763-1766 (1998).

[15] Mano V., Felisberti M. I., Matencio T., DePaoli M. A.: Thermal, mechanical and electrochemical behaviour of poly (vinyl chloride)/polypyrrole blends (PVC/PPy). Polymer, 37, 5165-5170 (1996).

[16] Brahim S., Guiseppi-Elie A.: Electroconductive hydrogels: Electrical and electrochemical properties of polypyrrole-poly(HEMA) composites. Electroanalysis, 17, 556-570 (2005).

[17] Park Y. H., Shin H. C., Lee Y., Son Y., Baik D. H.: Formation of polypyrrole copolymer in PSPMS precursor film by electrochemical polymerization. Molecular Crystals and Liquid Crystals Science and Technology: Section A, Molecular Crystals and Liquid Crystals, 327, 221-224 (1999).

[18] Stanke D., Hallensleben M., Toppare L.: Graftcopolymers and composites of poly(methyl methacrylate) and polypyrrole. Synthetic Metals, 73, 261-266 (1995).

[19] Kizilyar N., Toppare L., Önen A., Yagci Y.: Conducting copolymers of polypyrrole/polytetrahydrofuran. Polymer Bulletin, 40, 639-645 (1998).

[20] Park Y. H., Kim K. W., Jo W. H.: Preparation and characterization of conducting poly(acryloyl chloride)-g-polypyrrole copolymer. Polymers for Advanced Technologies, 13, 670-677 (2002).

[21] Tarkuc S., Sahin E., Toppare L., Colak D., Cianga I., Yagci Y.: Synthesis, characterization and electrochromic properties of a conducting copolymer of pyrrole functionalized polystyrene with pyrrole. Polymer, 47, 2001-2009 (2006).

[22] Kizilyar N., Toppare L., Önen A., Yagci Y.: Synthesis of conducting PPy/pTHF copolymers. Journal of Applied Polymer Science, 71, 713-720 (1999).

[23] Jerome C., Martinot L., Louette P., Jerome R.: Synthesis of new pyrrole-g-epsilon-caprolactone copolymers. Macromolecular Symposia, 153, 305-319 (2000). 
[24] Borole D. D., Kapadi U. R., Mahulikar P. P., Hundiwale D. G.: Electrochemical synthesis and characterization of conducting copolymer: Poly (o-aniline-co-otoluidine). Materials Letters, 60, 2447-2452 (2006).

[25] Mu S. L.: Poly(aniline-co-o-aminophenol) nanostructured network: Electrochemical controllable synthesis and electrocatalysis. Electrochimica Acta, 51, 34343440 (2006).

[26] Dhanalakshmi K., Saraswathi R.: Electrochemical preparation and characterization of conducting copolymers: poly(pyrrole-co-indole). Journal of Materials Science, 36, 4107-4115 (2001).

[27] Belbachir M., Bensaoula A.: Composition and method for catalysis using bentonites US patent $6,274,527$, USA (2001).

[28] Yahiaoui A., Belbachir M.: Ring-opening Polymerization of Styrene oxide with Maghnite- $\mathrm{H}^{+}$as ecocatalyst. Journal of Applied Polymer Science, 100, 16811687 (2006).

[29] Hachemaoui A., Yahiaoui A., Belbachir M.: Synthesis and characterization of of water soluble poly ( $\mathrm{N}$ acetyl) iminoethylene and poly (ethyleneimine) by ion- exchanged clay montmorillonite. Journal of Applied Polymer Science, 102, 3741-3750 (2006).

[30] Meghabar R., Megherbi A., Belbachir M.: Maghnite$\mathrm{H}^{+}$, an ecocatalyst for cationic polymerization of $\mathrm{N}$ vinyl-pyrrolidone. Polymer, 44, 4097-4100 (2003).
[31] Yan W., Li A. K., Hsu C. S., Zhang Z. C., Wan M. X.: Synthesis and characterization of poly(pyrroly/ methine). Chinese Journal of Polymer Science, 19, 499-501 (2001).

[32] Yahiaoui A., Belbachir M., Hachemaoui A.: An acid exchanged montmorillonite clay-catalyzed synthesis of polyepichlorhydrin. International Journal of Molecular Sciences, 4, 548-561 (2003).

[33] Yahiaoui A., Belbachir M., Hachemaoui A.: Cationic polymerization of 1,2-epoxypropane by an acid exchanged montmorillonite clay in the presence of ethylene glycol. International Journal of Molecular Sciences, 4, 572-585 (2003).

[34] Yahiaoui A., Belbachir M., Soutif J. C., Fontaine L.: Synthesis and structural analyses of Poly (1, 2-cyclohexene oxide) over solid acid catalyst. Materials Letters, 59, 759-767 (2005).

[35] Yahiaoui A., Belbachir M.: Macromonomers of epichlorohydrin and propylene oxide liquid polymers: synthesis and characterization. Mendeleev Communications, 15, 242-244 (2005).

[36] Yan W., Wei Z. X., Hsu C. S., Wan M. X.: Synthesis of microspheres of poly (pyrrolyl methane) by interfacial polymerization. Synthetic Metals, 135-136, 213 214 (2003).

[37] Leclerc M., Diaz F. M., Wegner G.: Structural analysis of poly(3-alkylthiophene)s. Die Makromolekulare Chemie, 190, 3105-3105 (1989). 